\section{An archaeology of mathematical structure in New Zealand}

\section{BILL BARTON}

\section{Introduction}

The purpose of this paper is to provide a framework within which we can make sense of the question What is the cultural component of mathematics ?'. In other words, can we describe mathematics in a way which is acceptable to mathematicians but which will also include culturally different approaches to the subject ?

The relationship between mathematics and culture also arises in the international arena as ethnomathematics. Research in this area explores the functions of mathematics in a cultural context (Bishop and Stigler \& Baranes) and thereby provides a framework for further anthropological study. This paper widens this framework so that mathematics itself (not just its functions) may be perceived in a cultural context.

\section{Mathematics in Te Ao Mäori}

Let us focus on those parts of Mäori cultural activity which we want to call mathematical to see how they relate to mathematics. We may thus identify the cultural aspects of western mathematics as well.

\section{Counting, measurement and design}

Discussions of Mäori mathematics often begin with the vocabulary and syntax of Mäori counting. The subject may then turn to Mäori art and design, or building and measuring techniques. At this point the discussion usually flags. Mäori games may be mentioned, or weaving techniques or net-making. In all these applied fields the mathematics is difficult to identify separately from the technique itself. Clearly, the early Mäori, like other peoples, counted, measured, designed, played, and developed technologies suitable for the time and situation in which they found themselves. But this does not equate to the elaborate functions and formalisations of mathematics as a discipline.

\section{Mythology}

One important function of mathematics is the power of recording, transmitting and developing technological knowledge. Consideration of Mäori technology such as navigation or canoe-building leads us to accept that there must have been a considerable mathematical component. How was such knowledge recorded? One of the answers is through mythology, pü rakau. A particular myth related, for example, the travels of a voyager in the mythical accounts of various land-forms. In this way the cartographical features of the journey are recorded: a new traveller need only travel from feature to feature to retrace the journey. The myth is the map. Important myths are like blank books. For example the myth of Kupe and his chase of the wheke to and around Aotearoa: in each area the myth will be embellished by the local people to explain, detail and record their particular coastal features.

Is mythology mathematics? No, but some of the functions are shared, and the mythological symbolism was probably elaborate, well-defined and subject to conventions - much like algebra.

\section{Religion}

Another sub-system of Mäori culture which had a mathematical function is karakia. How, for example, was a canoe constructed so that its design contained the collective knowledge of the best canoe-builders? If a building process was performed according to the spirituality of the situation, then this would ensure, among other things, that the process was repeated as it had been before. It is not too much to suppose that a set of symbols and conventions were present. It is likely that these were agreed upon by the experts and not necessarily understood by most people - the parallel with algebra or various mathematical processes is uncomfortably famili ar.

\section{Whare and other sub-systems}

The whare is another sub-system of Mäori culture which has a mathematical role. For example, the binding techniques of rafter joints have a symbolism which must be preserved by using the correct methods.

The 'decorative' arts of the whare (whakairo, köwhaiwhai, tukutuku) store the collective knowlede of the culture in an elaborate range of symbols, metaphors and reminders.

Thus mathematics can be regarded as a particular sub-system of western culture. Some of the functions of mathematics are performed by different sub-systems in other cultures. If this hypothesis is to be fully explored, then karakia, pü räkau, the whare and other areas need to be investigated by Mäori researchers for their symbols and conventions. 


\section{Whakapapa}

But mathematics is not its functions. It is a method of enquiry, a field of creative endeavour and a rational organisation of natural phenomena. Mathematics is a coherent, consistent and logical system, and forms the basis for rational thought. Can such an encompassing field be a cultural phenomenon?

What is the Manori equivalent to these descriptions of mathematics? Discussions with various informants have led to the conclusion that the Mäori world view is structured in terms of whakapapa. In other words the whakapapa is equal in power, pervasiveness and utility to the concept of logic or rationality is in Western thinking.

Whakapapa is a BIG word in cultural terms, etymologically it refers to the source of all things on earth, Papa-tu-a-nuku. Papa also has connotations of ordering in layers and of dimension. A possible translation of whakapapa is to bring into dimension'.

Whakapapa can apply to several different types of activity. On a practical level it is a straightforward means of measuring time. On a social level it is a body of knowledge to be learnt and manipulated for various purposes, e.g. reciting whakapapa may be a way of claiming territory. On a cognitive level whakapapa is a way of defining and relating to some origin, it is a method of thinking that can be applied to any organisation of knowledge. The creativity and poetry of whakapapa is also evident to those who have listened to Mãori oratory.

Evidence for the pervasiveness of this mode of cognition is the linguistic evidence of words relating to whakapapa. Key words in many areas of Măori culture have connotations of whakapapa: in weaving (aho), in land forms (hiwi), in plants (kăwai), in fishing (aho), weaponry (taotahi), in tattooing (kaka), in the human body (köiwi), in navigation (tätai), in the spiritual world (kauwhata) and in general, words like ara or kaha.

But the best argument for whakapapa as a world view is Mäori authority. Mäori Marsden describes the whakapapa of creation and then writes:

"Each [person] is an event within the one ongoing procession of nature and so is each created object. Whether this orientation is articulated or not, it remains the subconscious attitude of the Măori and is reflected in [their] whole mode of thinking and the expression of it in [their] language and its structure. ... Here we find the underlying attitudes to time and space: namely, that all things are relative, because all things are immersed within the stream of the cosmic process." (p2 18)

\section{The shape of mathematics}

The above account of mathematics in Mãori culture can assist us to set up a framework for cultural mathematics. Mathematics can now be seen as having three broad levels of definition: the levels of mathematical practice, mathematical technique and mathematical world view.

\section{Mathematical pactice}

This is the level of counting words, measuring systems and köwhaiwhai design. Everybody is a mathematician at this level, the practices are part of our daily lives at work or at leisure. Bishop (1988) defines six 'environmental activities' which give rise to mathematics. They are: counting, measiuring, locating, designing, playing and explaining. These are the activities of mathematical practice. They are multi-cultural. Examples of cross-cultural studies abound in counting systems, measuring systems, designs and games.

\section{Mathematical technique}

The second level relates to the manner or technique of mathematics. This is the level of the formalisations of Western mathematics: algebra, geometry, trigonometry and analysis. In the Mäori world we must look for mathematical functions to be performed in other sub-systems, for example in karakia or mythology. To access this 'mathematics' it is necessary to step into these sub-systems and use their codes, conventions and language. This is a rich area for future research, but it can only be done by researchers from the Måori culture. The level of technique is the level of the mathematical specialist, of explicit symbolisation and conventions, and of technological development. Here mathematics becomes interesting of itself.

\section{Mathematical world view}

This is the level of cognition and language. It includes the foundations and the philosophy of mathematics. In the Mäori world it embraces whakapapa and its connotations and denotations. It is a level of operation not usually considered separately because it is so pervasive and so abstract. At this level mathematics is acultural. Although it is not necessarily called mathematics, this area of thought has parallels in other cultures. The world view of another culture may not exactly coincide in form and function with mathematics (as understood in, say, western culture), but it will have equivalent importance. 


\section{Conclusion}

If mathematics is conceived as the amalgam of environmental activities such as counting, measuring, locating etc, then its cultural variations are the descriptions of these activities in each culture.

If mathematics is conceived as a sub-system of Western culture, then we must search for the ways in which the functions of mathematics are performed in the sub-systems of other cultures. If mathematics is conceived as the broad range of analytical thought then its cultural variability will encompass the language, imagery and cognition of each culture. This implies the possibility of research which can only be expressed in another language and which may be done by people without formal mathematical qualifications. Is this too great a challenge to the mathematical fraternity?

An important question to be answered now is: "What should be the cultural component of mathematics education ?". For example:

"Should whakapapa be part of the curriculum ?" These will be the critical questions in developing a truly bicultural mathematics education.

References:

Bishop, A J.Mathematical Enculturation, Kluwer Academic Publishers, Dordrecht, 1988

Marsden, M. "God, Man and Universe", Te Ao Hurihuri, King, M (ed), Longman Paul, 1975

Stigler, J W \& Baranes, R. "Culture and Mathe matics Learning", Review of Research in Education, Vol.15, 1988, pp253-306

This is an abridged version of a Stout Centre seminar on 19 September 1990., given by Bill Barton, Mathematics Education Unit, Victoria University. Research was made possible by a Claude McCarthy Fellowship. The complete paper is published as 'Occasional Paper 90-1', Mathematics Education Unit, Victoria University.

\section{NEW ZEALAND BOOKS}

\section{A quarterly review}

Subscribe now to this new quarterly appearing in early April and containing stimulating reviews of New Zealand books by John Roberts, Rod Alley, Kevin Ireland, Lauris Edmond, Roger Robinson, Harry Ricketts, Elizabeth Knox, Doreen d'Cruz, Melanie Nolan,Charles Croot, Iain Sharp, Annabel Cooper, Sarah Sandley, Nelson Wattie and Shelagh Cox.

A subscription for the first year costs only $\$ 20$, including postage and packing. Available also from all good bookshops.

SEND YOUR CHEgUE TO NEW ZEALAND BOOKS,. The Peppercorn Press, Box 28-063, Kelburn, Wellington 